\title{
Postpartum pulmonary circulation in pregnant rats with monocrotaline-induced pulmonary arterial hypertension
}

\author{
He Jing ${ }^{1}$, Mu Jin ${ }^{2}$, Yue Li ${ }^{3}$, Yuwei Sun ${ }^{1}$, Jiakai Lu ${ }^{1}$, Weiping Cheng ${ }^{1}$ \\ ${ }^{1}$ Department of Anesthesiology, Beijing Anzhen Hospital, Capital Medical University, Beijing Institute of Heart Lung and Blood Vessel Diseases, \\ Beijing, China; ${ }^{2}$ Department of Anesthesiology, Beijing Friendship Hospital, Capital Medical University, Beijing, China; ${ }^{3}$ Department of \\ Anesthesiology, Peking University People's Hospital, Beijing, China \\ Contributions: (I) Conception and design: H Jing, M Jin, J Lu, W Cheng; (II) Administrative support: M Jin, J Lu, W Cheng; (III) Provision of study \\ materials or patients: M Jin, Y Li, W Cheng; (IV) Collection and assembly of data: H Jing, Y Li, Y Sun; (V) Data analysis and interpretation: H Jing, \\ M Jin, J Lu, W Cheng; (VI) Manuscript writing: All authors; (VII) Final approval of manuscript: All authors. \\ Correspondence to: Weiping Cheng. Department of Anesthesiology, Beijing Anzhen Hospital, Capital Medical University, Beijing Institute of Heart \\ Lung and Blood Vessel Diseases, Anzhen Road 2\#, Beijing, China. Email: ch_eng9735@sina.com.
}

Background: This is the first study to evaluate changes in postpartum pulmonary circulation in a novel
pregnant rat model of monocrotaline (MCT)-induced pulmonary arterial hypertension (PAH).
Methods: Female rats were randomly divided into two groups: the MCT-treated pregnant group, in which
rats were injected with MCT ( $40 \mathrm{mg} / \mathrm{kg}$ ) at the age of 7 weeks, and the pregnant group, in which rats were
injected with the same volume of $0.9 \%$ saline at the same age. Rats from both groups were mated at the age
of 9 weeks. General condition information, hemodynamic data and pulmonary tissues were collected from
pregnant rats from the two groups on the 18 th day after successful mating (T1) and the 1 st (T2), 3rd (T3),
and 7 th days after delivery (T4). Results: The MCT-treated pregnant group exhibited a greater mean pulmonary artery pressure (mPAP) $(\mathrm{P}<0.01)$ and Fulton's Index $(\mathrm{P}<0.01)$ than the pregnant group at each time point. Lung tissues from the MCT-treated pregnant group showed pulmonary vascular hyperplasia and occlusive changes. The mPAP and the occluded pulmonary artery density in the MCT-treated pregnant group increased after delivery $(\mathrm{P}<0.01)$ and significantly increased at $\mathrm{T} 3$ compared with $\mathrm{T} 2(\mathrm{P}<0.05)$ but was not further increased at T4 $(\mathrm{P}>0.05)$.

Conclusions: Pregnant rats with PAH exhibited increased mPAP after delivery accompanied by a significant increase in the occluded pulmonary artery density, which may have contributed to the increased mortality rate of pregnant rats with $\mathrm{PAH}$ after delivery.

Keywords: Pulmonary artery hypertension (PAH); pregnancy; pulmonary circulation; postpartum

Submitted May 19, 2020. Accepted for publication Aug 26, 2020.

doi: $10.21037 /$ jtd-20-1966

View this article at: http://dx.doi.org/10.21037/jtd-20-1966

\section{Introduction}

Pulmonary artery hypertension $(\mathrm{PAH})$ is a rare and lifethreatening disease in pregnant women characterized by progressive increases in pulmonary artery pressure (PAP), pulmonary vascular resistance (PVR), inflammatory cell infiltration, vascular remodeling and occlusion of vessels with thrombi, which eventually lead to right ventricular failure, pulmonary hypertension crisis (PHC) and death $(1,2)$. A previous systematic review from 1978 to 1996 (3) showed that the mortality rate of pregnant women with $\mathrm{PAH}$ is $30-56 \%$, and recent data have indicated that the outcomes of pregnant women with $\mathrm{PAH}$ have improved with pharmacological therapy and a multidisciplinary approach (4-8).

It is generally believed that hemodynamic fluctuations caused by an increase in recurrent blood volume and decreased systemic vascular resistance (SVR), which occur during pregnancy and delivery, are the main causes of the 
high mortality rate of pregnant PAH patients $(6,9)$. In recent years, as comprehensive clinical management has improved, hemodynamic fluctuations observed in pregnant PAH patients have been relatively small, and reports of death during pregnancy and delivery have become increasingly rare (10). Most death of pregnant women with PAH occur within 1 month after delivery (11). More than half of the deaths in pregnant women with severe $\mathrm{PAH}$ occur within 1 week after delivery due to PHC caused by significantly increased PAP (12). Thus, the incidence of death after delivery, especially within 1 week after delivery, is high; however, this is inconsistent with clinicians' previous understanding of the development of this disease. Clinical data have shown that PAP increases in most patients who die within 1 week after delivery, especially patients with severe PAH or idiopathic PAH (IPAH) $(13,14)$. Theoretically, the circulatory system gradually stabilizes during this period, but PAP further increases. However, the specific causes of this further increase in PAP remain unknown. The exact changes of pulmonary circulation, which is the precondition to prevent further increases in PAP after delivery, have not yet been widely studied. Thus, this experiment mainly examined postpartum pulmonary circulation in a pregnant rat model of monocrotaline (MCT)-induced PAH to explore the cause of this further increase in PAP.

We present the following article in accordance with the ARRIVE reporting checklist (available at http://dx. doi. org/10. 21037/jtd-20-1966).

\section{Methods}

Six-week-old Sprague-Dawley (SD) rats [certificate number SYXK (Jing) 2016-0027] with a body weight of 150-175 g obtained from the Animal Resource Centre of Beijing Anzhen Hospital (Beijing, China) were included in this study. The rats were housed under a 12-h light/12-h dark cycle at $50-60 \%$ humidity and $20-22{ }^{\circ} \mathrm{C}$, and food and water were provided ad libitum. All experiments were approved by the Institutional Animal Care and Use Committee (Beijing Anzhen Hospital, Capital Medical University, Beijing, China) and conducted in accordance with the Guide for the Care and Use of Laboratory Animals published by the National Institutes of Health.

The female rats were randomly divided into two groups: the MCT-treated pregnant group and the pregnant group. The rats in the MCT-treated pregnant group were injected with MCT $(40 \mathrm{mg} / \mathrm{kg}$, Sigma-Aldrich Co, St. Louis, MO,
USA) to induce PAH at the age of 7 weeks. The rats in the pregnant group were injected with the same volume of $0.9 \%$ saline at the same age. Then, rats from both groups were mated at the age of 9 weeks. A follow-up study was carried out on rats that became pregnant in Anzhen Animal Laboratory (Beijing Anzhen Hospital, Capital Medical University, Beijing, China).

General condition information, hemodynamic data and pulmonary tissues were collected from pregnant rats from the two groups on the 18th day after successful mating (T1), the 1st day after delivery (T2), the 3 rd day after delivery (T3), and the 7th day after delivery (T4). The rats did not survive and continue their pregnancies after data collection. The rats from each group were numbered, and data collection time points were determined by drawing lots. The inclusion criterion was pregnancy within one week of the mating period. The exclusion criteria were as follows: no pregnancy within one week of the mating period and incomplete data collection caused by death or failure of the experimental operation. The timeline of the animal study is shown in Figure 1.

\section{PAH induction}

$\mathrm{PAH}$ was induced in rats from the MCT-treated pregnant group at the age of 7 weeks by a subcutaneous injection of MCT $(40 \mathrm{mg} / \mathrm{kg})$ into the neck. MCT was dissolved in $1 \mathrm{M}$ $\mathrm{HCl}$, and the $\mathrm{pH}$ was adjusted to 7.4 with $1 \mathrm{M} \mathrm{NaOH}$.

\section{Pregnancy establishment}

Rats from both groups were mated at the age of 9 weeks. One male rat was placed in a cage with $2-3$ female rats for 12 hours every night. Copulation was confirmed next morning by the presence of a copulation plug or spermatozoa in the vaginal smear. The day on which successful mating occurred was recorded. An enlarged abdomen on the 18th day after successful mating and the delivery of fetal mice were used as markers of pregnancy.

\section{Hemodynamic evaluation}

Rats that met the experimental criteria were anesthetized with $3 \%$ pentobarbital $(2-3 \mathrm{~mL} / \mathrm{kg}$, subcutaneously) and tracheally intubated for hemodynamic measurements. Mechanical ventilation (ALC-V8; Alcott Biotech Co., Ltd., Shanghai, China) was performed with a tidal volume of $7 \mathrm{~mL} / \mathrm{kg}$ and a respiratory rate of 50 breaths $/ \mathrm{min}$. 


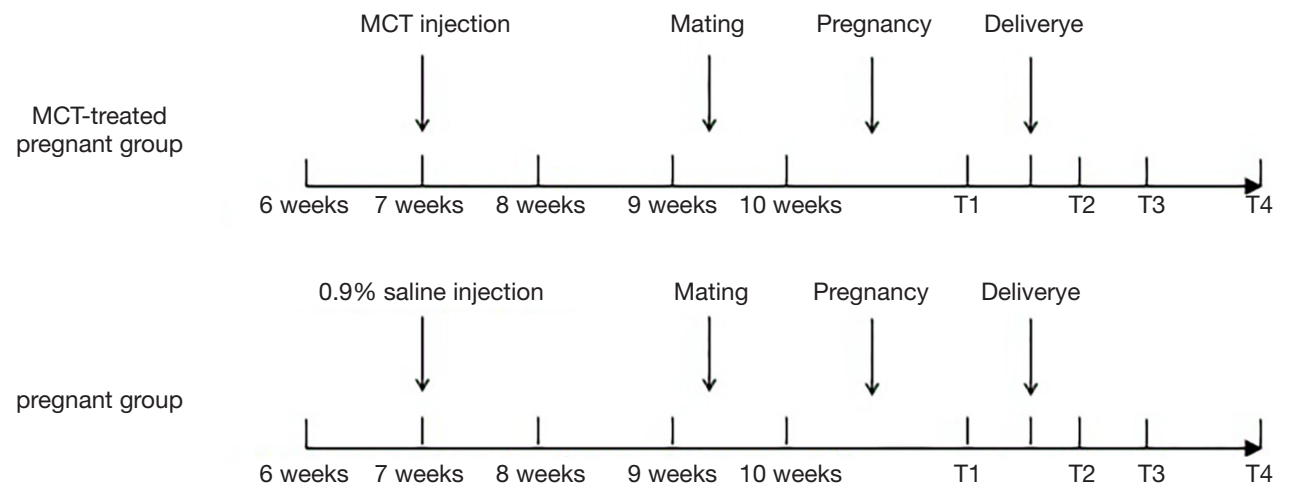

Figure 1 Timeline of the animal study. The female rats in the monocrotaline (MCT)-treated pregnant group were injected with MCT $(40 \mathrm{mg} / \mathrm{kg})$ at the age of 7 weeks. The female rats in the pregnant group were injected with the same volume of $0.9 \%$ saline at the same age. Rats from both groups were mated at the age of 9 weeks. General condition information, hemodynamic data and pulmonary tissues were collected from pregnant rats from the two groups on the 18th day after successful mating (T1) and the 1st (T2), 3rd (T3), and 7th days after delivery (T4).

The mean systemic arterial pressure (mSAP) was measured by using a catheter (24G, BD Insyte-W, Sandy, UT) inserted into the right femoral artery. The internal jugular vein was exposed through a $2-3 \mathrm{~cm}$ incision over the right ventral neck area. A polyethylene catheter connected to a pressure transducer was inserted into the right external jugular vein and threaded into the right ventricle and then the pulmonary artery to measure the mean PAP (mPAP). Each pressure reading is presented as the mean value of three measurements.

\section{Pulmonary vascular morphometric analysis}

The animals were sacrificed by injection of a highpotassium solution after hemodynamic measurement, and their lung tissues were harvested after thoracotomy for further analysis. The inferior lobes of the right lungs were extracted and then fixed in 4\% paraformaldehyde. The pulmonary lobes were embedded in paraffin, cut into 5- $\mu \mathrm{m}-$ thick sections and stained with hematoxylin and eosin (HE; ZLI-9615; ZSGB-BIO, Beijing, China). Paraffin-embedded sections were also stained with a Masson's Trichrome Stain Kit (Beijing Solarbio Science \& Technology Co., Ltd., Beijing, China) in accordance with the manufacturer's instructions. Ten to twenty pulmonary arteries per rat were studied microscopically (Eclipse 90i Microscope, Nikon, Japan) and analyzed (DS-Ri1-U3 digital camera, Nikon, Japan; Image-Pro Plus 6.0 software, Media Cybernetics, Washington, Rockville, USA) to evaluate pulmonary remodeling. The relative medial thickness of the pulmonary arteries was measured as follows: (ED - ID)/ED $\times 100 \%$ (ED, external diameter; ID, internal diameter). The pulmonary artery density was calculated by determining the number of small and medium pulmonary arteries (diameter: $50-200 \mathrm{um}$ ) per $\mathrm{mm}^{2}$ in an average of 10 fields/rat. The nonthickened and occluded pulmonary artery densities were also analyzed. All of these morphometric studies were conducted in a blinded manner.

\section{Measurement of right ventricular bypertrophy}

Harvest the heart by cutting at the root of the aorta. And then dissect the heart to separate the right ventricle (RV) free wall from the left ventricle (LV) and septum (S). Weigh the $\mathrm{RV}$ and $\mathrm{LV}+$ septum $(\mathrm{LV}+\mathrm{S})$ to calculate a Fulton index $(\mathrm{RV} / \mathrm{LV}+\mathrm{S})$, which quantifies the degree of $\mathrm{RV}$ hypertrophy.

\section{Statistical analysis}

The values are expressed as the mean $\pm \mathrm{SD}$. The significance of the differences was calculated by one-way ANOVA and the chi-square test using the SPSS 23.0 statistical package. A $P$ value $<0.05$ was considered significant.

\section{Results}

\section{General condition of the rats}

A total of 258 female and 80 male SD rats were included in 
Table 1 The weights of the rats $(\mathrm{n}=15)$

\begin{tabular}{|c|c|c|c|c|}
\hline Weight (g) & $\mathrm{T} 1$ & $\mathrm{~T} 2$ & T3 & $\mathrm{T} 4$ \\
\hline MCT-treated pregnant group & $339.6 \pm 36.8^{\circ 0}$ & $235.6 \pm 32.4^{\star \star 00}$ & $230.6 \pm 37.1^{\star \star \# \circ \mathrm{O}}$ & $219.6 \pm 40.2^{\star \star \# \circ \circ}$ \\
\hline
\end{tabular}

Data are mean \pm SD. T1, the 18th day after successful mating; T2, the 1st day after delivery; T3, the 3rd day after delivery; T4, the 7th day after delivery. ${ }^{* *} \mathrm{P}<0.01$ vs. $\mathrm{T} 1 ;{ }^{\#} \mathrm{P}<0.05$ vs. the previous time point; ${ }^{\circ} \mathrm{P}<0.01$ vs. the pregnant group.

Table 2 The mSAP and mPAP of the rats $(\mathrm{n}=15)$

\begin{tabular}{|c|c|c|c|c|}
\hline & $\mathrm{T} 1$ & $\mathrm{~T} 2$ & T3 & $\mathrm{T} 4$ \\
\hline \multicolumn{5}{|l|}{ mSAP $(\mathrm{mmHg})$} \\
\hline MCT-treated pregnant group & $49.83 \pm 5.83$ & $50.35 \pm 5.27$ & $49.93 \pm 7.32$ & $49.11 \pm 6.18$ \\
\hline \multicolumn{5}{|l|}{ mPAP $(\mathrm{mmHg})$} \\
\hline MCT-treated pregnant group & $26.25 \pm 3.15^{\circ \circ}$ & $32.17 \pm 4.47^{\star \star 00}$ & $39.54 \pm 4.94^{\star \star \# \circ \mathrm{o}}$ & $38.36 \pm 4.69^{\star * \circ \circ}$ \\
\hline
\end{tabular}

Data are mean \pm SD. mSAP, mean systemic arterial pressure; mPAP, mean pulmonary artery pressure; T1, the 18th day after successful mating; T2, the 1st day after delivery; $\mathrm{T} 3$, the 3rd day after delivery; $\mathrm{T} 4$, the 7 th day after delivery. ${ }^{*} \mathrm{P}<0.01$ vs. $\mathrm{T} 1 ;{ }^{*} \mathrm{P}<0.05$ vs. the previous time point; ${ }^{\circ} \mathrm{P}<0.01$ vs. the pregnant group.

this study. Male rats were used only for mating.

Eighty-eight female rats were assigned to the pregnant group and were mated. Sixty of the rats successfully became pregnant, yielding a pregnancy rate of $68.2 \%$. There was no significant change in the general condition of these rats, and none of the rats died.

A total of 170 female rats were assigned to the MCTtreated pregnant group. One week after MCT injection, the rats began to show decreased activity; dark, erect, and lusterless hair; rapid respiration; decreased appetite; and emaciation. Thirteen $(7.6 \%)$ of the rats died before mating; thus, a total of 157 rats were mated. Eight-one rats successfully became pregnant, after which their activity further decreased. The pregnancy rate was $51.6 \%$. Of these pregnant rats, 1 rat died before giving birth, 6 rats died within 1 day after delivery, 10 rats died between 2 days and 3 days after delivery, and 4 rats died between 4 days and 7 days after delivery. The mortality rate of the pregnant rats from the MCT-treated pregnant group from pregnancy to 7 days after delivery was $25.9 \%$.

None of the data for either group were lost due to failure of the experimental operation. Sixty rats from each group, including 15 rats at each time point, were included in the data analysis.

The weights of rats from the MCT-treated pregnant group was significantly lower than that of the rats from the pregnant group at each time point $(\mathrm{P}<0.01)$. The weights of the rats from both groups were significantly lower at $\mathrm{T} 2$ than at $\mathrm{T} 1(\mathrm{P}<0.01)$ and decreased gradually after delivery $(\mathrm{P}<0.05)$ (Table 1).

\section{Hemodynamic evaluation}

There was no significant difference in mSAP between the two groups $(\mathrm{P}>0.05)$. There was no significant change in mSAP between $\mathrm{T} 1$ and $\mathrm{T} 2, \mathrm{~T} 3$ or $\mathrm{T} 4$ in either of the groups $(\mathrm{P}>0.05)$. The mPAP of the pregnant group was not obviously changed at any of the time points $(\mathrm{P}>0.05)$. The MCT-treated pregnant group exhibited a greater mPAP $(\mathrm{P}<0.01)$ than the pregnant group at each time point. In the MCT-treated pregnant group, the mPAP was significantly increased at T2, T3 and T4 compared to T1 $(\mathrm{P}<0.01)$. The mPAP of the MCT-treated pregnant group was significantly increased at $\mathrm{T} 3$ compared with $\mathrm{T} 2(\mathrm{P}<0.05)$ but was not further increased at $\mathrm{T} 4(\mathrm{P}>0.05)$ (Table 2).

\section{Pulmonary vascular morphometry}

There was no significant change in lung tissues from the pregnant group at any of the time point. The lung tissues 

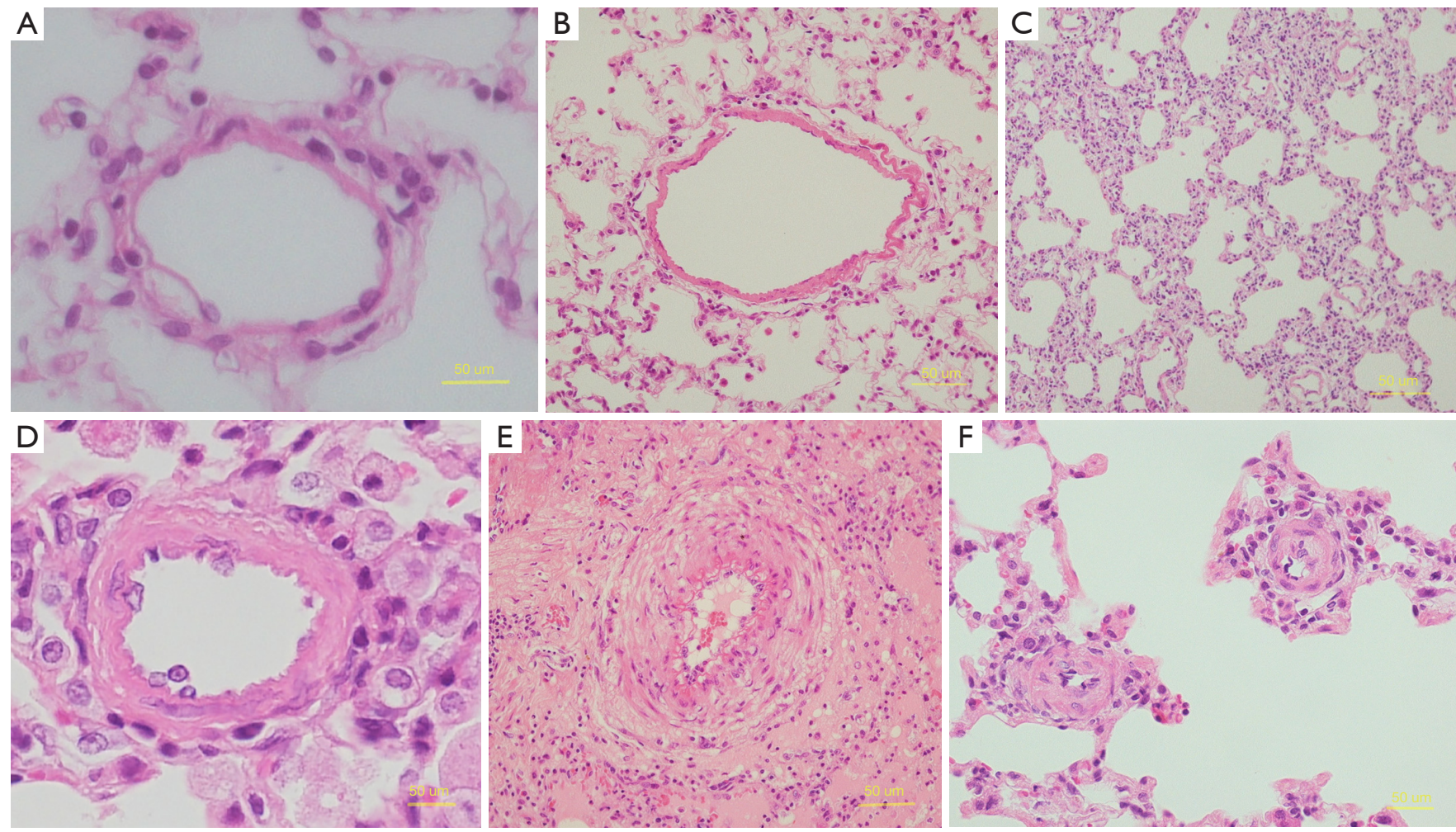

Figure 2 Pulmonary arterial morphology of rat tissues under a light microscope (HE, 400x). Pulmonary arteries from (A) the pregnant group before delivery, (B,C) the pregnant group after delivery, (D) the MCT-treated pregnant group before delivery, and (E,F) the MCTtreated pregnant group after delivery.

from the MCT-treated pregnant group showed vascular endodermal hyperplasia, microaneurysms and vascular occlusion of the pulmonary arterioles. In the MCT-treated pregnant group, the smooth muscle and elastic fiber layers of the pulmonary arterioles were thickened, and the size of the vascular cavity was decreased (Figure 2).

Compared with those from the pregnant group, tissues from the MCT-treated pregnant group exhibited increases in the relative medial thickness, pulmonary artery density and occluded pulmonary artery density and a decrease in the nonthickened pulmonary artery density at each time point $(\mathrm{P}<0.01)$.

There were no significant changes in the relative medial thickness, pulmonary artery density or nonthickened pulmonary artery density between $\mathrm{T} 1$ and $\mathrm{T} 2, \mathrm{~T} 3$ or $\mathrm{T} 4$ in either of the groups $(\mathrm{P}>0.05)$, but the occluded pulmonary artery density in the pregnant MCT group was significantly increased at $\mathrm{T} 2, \mathrm{~T} 3$ and $\mathrm{T} 4$ compared to $\mathrm{T} 1 \quad(\mathrm{P}<0.01)$. The occluded pulmonary artery density was significantly increased at $\mathrm{T} 3$ compared with $\mathrm{T} 2(\mathrm{P}<0.05)$ but was not further increased at $\mathrm{T} 4(\mathrm{P}>0.05)$ (Table 3).

\section{Fulton index}

The MCT-treated pregnant group exhibited a greater Fulton index $(\mathrm{P}<0.01)$ than the pregnant group at each time point. There were no significant changes in the Fulton index between $\mathrm{T} 1$ and $\mathrm{T} 2, \mathrm{~T} 3$ or $\mathrm{T} 4$ in either of the groups $(\mathrm{P}>0.05)$ (Table 4).

\section{Discussion}

This experiment is the first to evaluate changes in postpartum pulmonary circulation in a novel pregnant rat model of MCT-induced PAH. The experimental results showed that pregnant rats with MCT-induced PAH exhibited higher mPAP than normal pregnant rats and showed RV hypertrophy, pulmonary vascular endodermal hyperplasia, microaneurysms and vascular occlusion of the pulmonary arterioles. The mPAP of pregnant rats with 
Table 3 Relative medial thickness and pulmonary artery, nonthickened pulmonary artery density and occluded pulmonary artery density (n=15)

\begin{tabular}{|c|c|c|c|c|}
\hline & $\mathrm{T} 1$ & $\mathrm{~T} 2$ & T3 & $\mathrm{T} 4$ \\
\hline Pregnant group & $28.74 \pm 3.37$ & $30.30 \pm 3.58$ & $29.75 \pm 3.32$ & $29.35 \pm 3.41$ \\
\hline MCT-treated pregnant group & $35.69 \pm 4.04^{\circ 0}$ & $35.26 \pm 4.41^{\circ \circ}$ & $34.64 \pm 3.98^{\circ 0}$ & $35.94 \pm 4.71^{\circ \circ}$ \\
\hline \multicolumn{5}{|c|}{ Pulmonary artery density (per $\mathrm{mm}^{2}$ ) } \\
\hline MCT-treated pregnant group & $7.67 \pm 2.81^{\circ 0}$ & $7.93 \pm 1.97^{\circ \circ}$ & $7.82 \pm 1.83^{\circ \circ}$ & $8.01 \pm 2.15^{\circ \circ}$ \\
\hline \multicolumn{5}{|c|}{ Nonthickened pulmonary artery density (per $\mathrm{mm}^{2}$ ) } \\
\hline Pregnant group & $4.99 \pm 0.45$ & $4.92 \pm 0.51$ & $4.72 \pm 0.34$ & $4.88 \pm 0.52$ \\
\hline MCT-treated pregnant group & $1.76 \pm 0.20^{\circ \circ}$ & $1.83 \pm 0.03^{\circ \circ}$ & $1.69 \pm 0.02^{\circ \circ}$ & $1.78 \pm 0.03^{\circ \circ}$ \\
\hline MCT-treated pregnant group & $0.09 \pm 0.03^{\circ 0}$ & $3.13 \pm 0.42^{\star * 00}$ & $3.73 \pm 0.49^{\star \star \# \circ \circ ~}$ & $3.06 \pm 0.41^{\star * 00}$ \\
\hline
\end{tabular}

Data are mean \pm SD. T1, the 18th day after successful mating; T2, the 1st day after delivery; T3, the 3rd day after delivery; T4, the 7th day after delivery. ${ }^{* *} \mathrm{P}<0.01$ vs. $\mathrm{T} 1 ;{ }^{\#} \mathrm{P}<0.05$ vs. the previous time point; ${ }^{\circ} \mathrm{P}<0.01$ vs. the pregnant group.

Table 4 Fulton index of the rats $(\mathrm{n}=15)$

\begin{tabular}{lcccc}
\hline Fulton index (\%) & T1 & T2 & T3 & T4 \\
\hline Pregnant group & $26.81 \pm 7.0$ & $26.71 \pm 7.4$ & $27.63 \pm 8.6$ & $26.38 \pm 6.9$ \\
MCT-treated pregnant group & $53.7 \pm 7.9^{\circ \circ}$ & $55.4 \pm 9.1^{\circ 0}$ & $54.6 \pm 8.3^{\circ 0}$ & $55.3 \pm 9.6^{\circ 0}$ \\
\hline
\end{tabular}

Data are mean \pm SD. T1, the 18th day after successful mating; T2, the 1st day after delivery; T3, the 3rd day after delivery; T4, the 7th day after delivery. ${ }^{\circ 0} \mathrm{P}<0.01$ vs. the pregnant group.

PAH increased further after delivery, and most deaths occurred between 1 and 3 days after delivery. There was no significant change in the hyperplasticity of the pulmonary arteries after delivery, but occlusion of the pulmonary arteries was further aggravated; this undoubtedly led to the increase in PAP and may have contributed to the high mortality rate observed after delivery.

\section{Rat model of PAH in pregnancy}

At present, there are several models of PAH that accurately simulate human disease $(15,16)$, but there have been no studies on animal models of PAH in pregnancy (17). The MCT-induced PAH rat model is a classical animal model that mimics several key aspects of human $\mathrm{PAH}$, including vascular remodeling, smooth muscle cell proliferation, endothelial dysfunction, inflammatory cytokine upregulation, and right ventricle failure and requires only a single drug injection (18-20). It also precisely simulates the pathophysiological changes that occur in IPAH (21), which is the most severe type of $\mathrm{PAH}$ in pregnancy patients and causes the highest mortality $(13,22)$. We established a new animal model—a pregnant rat model of MCT-induced PAH—based on this model.

MCT $(30-80 \mathrm{mg} / \mathrm{kg}$ ) is commonly used to generate experimental models of PAH in rats. The dose required to induce PAH in rats in unclear, but most studies have used $60 \mathrm{mg} / \mathrm{kg}$ (23-25). However, our preliminary experiments showed that rats injected with $60 \mathrm{mg} / \mathrm{kg}$ MCT showed much higher mPAP and mortality than rats injected with $40 \mathrm{mg} / \mathrm{kg}$ MCT. Therefore, we finally chose this low dose of MCT $(40 \mathrm{mg} / \mathrm{kg})$ to induce PAH in rats to ensure that most rats were able to tolerate pregnancy and survive postpartum (26).

In this study, the rats in the MCT-treated pregnant group exhibited higher mPAP and Fulton index than those in the 
pregnant group, and the lung tissues of the MCT-treated pregnant rats also showed prominent proliferative and occlusive changes in the pulmonary arteries. This suggested that the model met the criteria of PAH diagnosis (27). An enlarged abdomen on the 18th day after successful mating and delivery of fetal mice indicated successful establishment of pregnancy. These indicators demonstrated that a pregnant rat model of MCT-induced $\mathrm{PAH}$ was successfully established. The success rate of model establishment (number of pregnant rats with $\mathrm{PAH} /$ total number of rats in the MCT-treated pregnant group) was $47.6 \%$.

The pregnancy rate of the MCT-treated pregnant group (51.6\%) was lower than that of the pregnant group (68.2\%), which suggested that PAH reduced the ability of rats to become pregnant 2 weeks after MCT injection. The mortality rate of pregnant rats with $\mathrm{PAH}$ was $25.9 \%$, and none of the rats died during delivery. Most deaths occurred between 1 and 3 days after delivery. These observations are consistent with clinical findings (28). We believe that the main cause of death of the rats was multiple organ failure (MOF) caused by the significantly increased PAP after delivery. All of these results further demonstrate that this model can accurately simulate the clinical situation.

\section{Changes in postpartum pulmonary circulation}

In addition to the MCT-induced significant differences between the two groups, other differences were also observed after delivery. As the gestation period of SD rats is approximately 18 days, $\mathrm{T} 1$, which was the $18^{\text {th }}$ day after successful mating, was the prenatal period.

To monitor changes in pulmonary circulation, we analyzed PAP, Fulton index and pulmonary vascular morphometry $(29,30)$. Dynamic monitoring of PAP can provide a timely understanding of changes in PVR, which can be regulated by many factors, such as longterm chronic factors (pulmonary vascular hyperplasia and occlusion) and short-term rapid factors (circulation, blood flow, and left and right heart function). Fulton's Index was used to evaluate RV hypertrophy, which does not change significantly in a short time and is irreversible. Indicators of pulmonary vascular hyperplasia in pulmonary vascular morphometric analyses, such as the relative medial thickness of the pulmonary arteries, pulmonary artery density and nonthickened pulmonary artery density, are influenced by long-term chronic factors; these factors are difficult to regulate in the short term, and thus these changes are irreversible (31). The occluded pulmonary artery density is not only affected by changes in pulmonary vascular proliferation but also can be regulated by some factors and altered in the short term (32). Through comprehensive evaluation of the above indexes, we can infer changes in pulmonary circulation and determine whether there are some influencing factors that we have not yet identified.

PAP increased significantly in pregnant rats with PAH after delivery. Although this result seems to be consistent with clinical findings, there are differences. The main difference is that the rats in this experiment were not treated. Most patients receive different degrees of intervention treatment during the perinatal period, and the PAP of many surviving patients does not necessarily continue to increase after delivery. According to our clinical experience, the outcomes of patients who experience further increases in PAP after delivery may not be favorable; however, outcomes are better in patients who do not experience further increases in $\operatorname{PAP}(11,33)$.

There were no further hyperplastic changes in the pulmonary vessels and RV within 7 days after delivery. However, the occluded pulmonary artery density increased significantly after delivery, indicating that more pulmonary arteries exhibited occlusive changes. Notably, PAP and the occlusive pulmonary artery density were significantly increased on the third day of the postpartum period, at which point, most deaths occurred. This result is consistent with clinical findings.

Occlusive changes in the pulmonary arteries and changes in PAP occur simultaneously after delivery, but no other serious hyperplastic changes occur in the pulmonary arteries themselves. It is very difficult to regulate proliferation in the pulmonary arteries in the short term, but pulmonary artery occlusion is affected by many other factors in addition to proliferative changes (34). The occlusive changes in the pulmonary arteries undoubtedly led to an increase in PAP and may have contributed to the higher mortality rate of pregnant rats with $\mathrm{PAH}$ after delivery.

We speculate that there are two explanations for these observations: some factors that cause pulmonary artery occlusion are newly induced or increased after delivery or some factors that can reduce pulmonary artery occlusion are abolished or weakened after delivery. Regardless of the reason, these factors likely exist in both normal rats and rats with $\mathrm{PAH}$; however normal rats do not exhibit changes in pulmonary vascular occlusion (35). This indicates that rats with $\mathrm{PAH}$ may be more sensitive to these factors, possibly due to damage to the pulmonary vessels. Recent research results have shown that the inflammatory response, 
hormone regulation, gene regulation and high alveolar pressure all lead to pulmonary vascular occlusion (36). The factors that are obviously changed during the perinatal period and are more sensitive to pulmonary vessel damage may be the causes of postpartum pulmonary vascular occlusion (37). Our follow-up research will focus on exploring the causes of postpartum pulmonary vascular occlusion and providing targets for prevention and treatment.

However, there are some limitations in this study. Due to the limitations of the experimental conditions and technical difficulties, PVR was not measured; however the change in PVR can be estimated by changes in PAP, meaning that the absence of these data had no effect on the analysis of the experimental results.

\section{Conclusions}

Pregnant rats with MCT-induced PAH had higher mPAP and Fulton's Index than normal pregnant rats and showed vascular endodermal hyperplasia, microaneurysms and vascular occlusion of the pulmonary arterioles. In pregnant rats with $\mathrm{PAH}$, a significant increase in $\mathrm{mPAP}$ after delivery was accompanied by a significant increase in occluded pulmonary artery density, which may have contributed to the higher mortality rate of pregnant rats with $\mathrm{PAH}$ after delivery.

\section{Acknowledgments}

The authors would like to thank Professor Mu Jin for excellent technical support and Professor Jiakai Lu for critically reviewing the manuscript.

Funding: None.

\section{Footnote}

Reporting Checklist: The authors have completed the ARRIVE reporting checklist. Available at http://dx. doi. org/10. 21037/jtd-20-1966

Data Sharing Statement: Available at http://dx. doi. org/10. 21037/jtd-20-1966

Conflicts of Interest: All authors have completed the ICMJE uniform disclosure form (available at http://dx. doi. org/10.21037/jtd-20-1966). The authors have no conflicts of interest to declare.
Ethical Statement: The authors are accountable for all aspects of the work in ensuring that questions related to the accuracy or integrity of any part of the work are appropriately investigated and resolved. All experiments were approved by the Institutional Animal Care and Use Committee (Beijing Anzhen Hospital, Capital Medical University, Beijing, China) and conducted in accordance with the Guide for the Care and Use of Laboratory Animals published by the National Institutes of Health.

Open Access Statement: This is an Open Access article distributed in accordance with the Creative Commons Attribution-NonCommercial-NoDerivs 4.0 International License (CC BY-NC-ND 4.0), which permits the noncommercial replication and distribution of the article with the strict proviso that no changes or edits are made and the original work is properly cited (including links to both the formal publication through the relevant DOI and the license). See: https://creativecommons.org/licenses/by-nc-nd/4.0/.

\section{References}

1. Leuchte HH, Ten Freyhaus H, Gall H, et al. Risk stratification strategy and assessment of disease progression in patients with pulmonary arterial hypertension: Updated Recommendations from the Cologne Consensus Conference 2018. Int J Cardiol 2018;272S:20-9.

2. Coons JC, Pogue K, Kolodziej AR, et al. Pulmonary Arterial Hypertension: Pharmacotherapeutic Update. Curr Cardiol Rep 2019;21:141.

3. Weiss BM, Zemp L, Seifert B, et al. Outcome of Pulmonary Vascular Disease in Pregnancy: A Systematic Overview From 1978 Through 1996. J Am Coll Cardiol 1998;31:1650-7.

4. Roos-Hesselink J, Baris L, Johnson M, et al. Pregnancy outcomes in women with cardiovascular disease: evolving trends over 10 years in the ESC Registry Of Pregnancy And Cardiac disease (ROPAC). Eur Heart J 2019;40:3848-55.

5. Lu J, Cheng W, Huang J. Report on Cardiac Anesthesia Progress and Challenges in China. J Cardiothorac Vasc Anesth 2018;32:2365-71.

6. Sliwa K, Baris L, Sinning C, et al. Pregnant Women With Uncorrected Congenital Heart Disease: Heart Failure and Mortality. JACC Heart Fail 2020;8:100-10.

7. Olsson KM, Channick R. Pregnancy in pulmonary arterial hypertension. Eur Respir Rev 2016;25:431-7. 
8. Halpern DG, Weinberg CR, Pinnelas R, et al. Use of Medication for Cardiovascular Disease During Pregnancy: JACC State-of-the-Art Review. J Am Coll Cardiol 2019;73:457-76.

9. Hohmann C, Dumitrescu D, Gerhardt F, et al. Highrisk pregnancy in a patient with pulmonary arterial hypertension due to congenital heart disease (PAH-CHD) with temporary shunt inversion and deoxygenation. Pulm Circ 2019;9:2045894019835649.

10. Li Q, Dimopoulos K, Liu T, et al. Peripartum outcomes in a large population of women with pulmonary arterial hypertension associated with congenital heart disease. Eur J Prev Cardiol 2019;26:1067-76.

11. Zhang LL, Zhang J. Analysis of hemodynamics and outcomes of pregnant women with congenital heart disease-pulmonary arterial hypertension. Zhonghua Fu Chan Ke Za Zhi 2019;54:438-44.

12. Miao HX, Feng SH, Wang C, et al. Analysis of maternal deaths with cardiovascular diseases in Shanghai obstetric heart disease intensive care unit within twenty-six years. Zhonghua Fu Chan Ke Za Zhi 2019;54:826-32.

13. Zhang J, Lu J, Zhou X, et al. Perioperative Management of Pregnant Women With Idiopathic Pulmonary Arterial Hypertension: An Observational Case Series Study From China. J Cardiothorac Vasc Anesth 2018;32:2547-59.

14. Rashidi F, Sate H. Pregnancy outcome in a pregnant patient with idiopathic Pulmonary Arterial Hypertension: a case report and review of the literature. J Med Case Rep 2018;12:31.

15. Provencher S, Archer SL, Ramirez FD, et al. Standards and Methodological Rigor in Pulmonary Arterial Hypertension Preclinical and Translational Research. Circ Res 2018;122:1021-32.

16. Sztuka K, Jasińska-Stroschein M. Animal models of pulmonary arterial hypertension: A systematic review and meta-analysis of data from 6126 animals. Pharmacol Res 2017;125:201-14.

17. Sztuka K, Orszulak-MichalakD, Jasińska-Stroschein M. Systematic review and meta-analysis of interventions tested in animal models of pulmonary hypertension. Vascul Pharmacol 2018;110:55-63.

18. Wilson DW, Segall HJ, Pan LC, et al. Mechanisms and pathology of monocrotaline pulmonary toxicity. Crit Rev Toxicol 1992;22:307-25.

19. Xiao R, Su Y, Feng T, et al. Monocrotaline Induces Endothelial Injury and Pulmonary Hypertension by Targeting the Extracellular Calcium-Sensing Receptor. J Am Heart Assoc 2017;6:6.
20. Zhao X, Bai X, Li JL, et al. Sevoflurane improves circulatory function and pulmonary fibrosis in rats with pulmonary arterial hypertension through inhibiting NF- B signaling pathway. Eur Rev Med Pharmacol Sci 2019;23:10532-40.

21. Nogueira-Ferreira R, Vitorino R, Ferreira R, et al. Exploring the monocrotaline animal model for the study of pulmonary arterial hypertension: A network approach. Pulm Pharmacol Ther 2015;35:8-16.

22. Wang $\mathrm{Y}, \mathrm{Xu} \mathrm{H}, \mathrm{Li} \mathrm{H}$, et al. Association of hemodynamics during caesarean section, outcomes after caesarean section and hormone changes with different anesthesia in pregnant women with severe pulmonary arterial hypertension. Exp Ther Med 2018;15:4731-6.

23. Zimmer A, Teixeira RB, Bonetto JHP, et al. Role of inflammation, oxidative stress, and autonomic nervous system activation during the development of right and left cardiac remodeling in experimental pulmonary arterial hypertension. Mol Cell Biochem 2020;464:93-109.

24. Aliotta JM, Pereira M, Wen S, et al. Exosomes induce and reverse monocrotaline-induced pulmonary hypertension in mice. Cardiovasc Res 2016;110:319-30.

25. Cai C, Xiang Y, Wu Y, et al. Formononetin attenuates monocrotaline induced pulmonary arterial hypertension via inhibiting pulmonary vascular remodeling in rats. Mol Med Rep 2019;20:4984-92.

26. Lachant DJ, Meoli DF, Haight D, et al. Low dose monocrotaline causes a selective pulmonary vascular lesion in male and female pneumonectomized rats. Exp Lung Res 2018;44:51-61.

27. Stenmark KR, Frid MG, Graham BB, et al. Dynamic and diverse changes in the functional properties of vascular smooth muscle cells in pulmonary hypertension. Cardiovasc Res 2018;114:551-64.

28. Sommer N, Ghofrani A, Pak O, et al. Current and future treatments of pulmonary arterial hypertension. $\mathrm{Br} \mathrm{J}$ Pharmacol 2020;7. [Epub ahead of print].

29. MacIver DH, Adeniran I, MacIver IR, et al. Physiological mechanisms of pulmonary hypertension. Am Heart J 2016;180:1-11.

30. Zargaran A, Arezaei H. Discovery of the pulmonary circulation. Eur Heart J 2016;37:3494.

31. Guazzi M, Naeije R. Pulmonary Hypertension in Heart Failure: Pathophysiology, Pathobiology, and Emerging Clinical Perspectives. J Am Coll Cardiol 2017;69:1718-34.

32. Langer T, Castagna V, Brusatori S, et al. Short-term Physiologic Consequences of Regional Pulmonary Vascular Occlusion in Pigs. Anesthesiology 2019; 131: 
336-43.

33. Arendt KW, Lindley KJ. Obstetric anesthesia management of the patient with cardiac disease. Int J Obstet Anesth 2019;37:73-85.

34. Takeuchi T, Sakao S, Kato F, et al. Pulmonary hemodynamics are correlated with intimal lesions in a rat model of severe PAH: attenuation of pulmonary vascular remodelling with ambrisentan. Histol Histopathol 2016;31:1357-65.

35. Mashimo S, Chubachi S, Tsutsumi A, et al. Relationship between diminution of small pulmonary vessels and

Cite this article as: Jing H, Jin M, Li Y, Sun Y, Lu J, Cheng W. Postpartum pulmonary circulation in pregnant rats with monocrotaline-induced pulmonary arterial hypertension. J Thorac Dis 2020;12(10):5475-5484. doi: 10.21037/jtd-20-1966 emphysema in chronic obstructive pulmonary disease. Clin Imaging 2017;46:85-90.

36. Fayyaz AU, Edwards WD, Maleszewski JJ, et al. Global Pulmonary Vascular Remodeling in Pulmonary Hypertension Associated With Heart Failure and Preserved or Reduced Ejection Fraction. Circulation 2018;137:1796-810.

37. MarraAM, BenjaminN, EichstaedtC, et al. Gender-related differences in pulmonary arterial hypertension targeted drugs administration. Pharmacol Res 2016;114:103-9. 